\title{
JANE, LA MUJER PROVIDENCIAL DE PEDRO EN «LA SOMBRA DEL CIPRÉS ES ALARGADA»DE MIGUEL DELIBES
}

Sheryl Lynn Postman

Para entender mejor la relación entre Jane, la mujer providencial de Pedro y Beatrice, de Dante, será necesario dar un breve resumen del argumento de La sombra del ciprés es alargada: un niño de diez años, huérfano, criado por su tío, es encargado a don Mateo Lesmes para que lo eduque hasta que termine su bachillerato. Todo en este ambiente, el lugar y la casa, es monótono, triste y frío. Don Mateo, pesimista, influye sobre Pedro y sobre Alfredo, otro estudiante con quien Pedro trata de cultivar una amistad intima. En el momento en que los dos han conseguido tal amistad, muere Alfredo. Su muerte tanto como la filosofia negativa del maestro, tendrán una influencia enorme en la vida de Pedro y, por consiguiente, cambiarán su manera de ser. Este cambio dura hasta que, años después, llega a conocer y luego a casarse con Jane, muchacha norteamericana. El ciclo se cierra cuando la esposa, inesperadamente, muere.

Para crear un ambiente apropiado, Miguel Delibes sitúa la acción de esta novela en la antigua ciudad española de Ávila. Ávila es una ciudad medieval. Es, también, una ciudad famosa por sus murallas, concepto que tendrá muchos efectos en la vida de nuestro protagonista, Pedro. La arquitectura de este período se manifiesta en castillos y muros'. Esta idea de aislamiento tendrá un efecto profundo en la vida de Pedro.

En las sociedades arcaicas y tradicionales, el mundo adyecente es concebido como un microcosmos. A los límites de este mundo cerrado empieza el dominio de lo desconocido y de lo amorfo. A este lado de este espacio p. 64 .

' Charles E. Chapman, A History of Spain. New York, The Macmillan Company, 1948, 
familiar, hay 'lo desconocido y la región peligrosá de los diablos, los fantasmas, los muertos y los extranjeros: el caos, la muerte o la noche.

Para el mundo arcaico en general, los enemigos amenazando este microcosmos eran peligrosos, no en su capaciaad de seres humanos, sino porque encarnaban los poderes hóstiles y destructivos. Es muy probable que estas defensas de regiones habitadas y ciudades empezaran como defensas mágicas; estas defensas fueron establecidas a impedir las incursiones de espíritus malos más bien que un ataque actual. Asi que en la Edad Media, las murallas de una ciudad fueron, ritualmente, consegradas como una defensa del Diablo, la enfermedad y la muerte ${ }^{2}$.

La concepción filosófica de este universo feudal supone una idea de totalidad y comunidad orgánica, en que no caben las individualidades ni el aislamiento dentro de la sociedad. Todos formaban parte de un todo ${ }^{3}$.

Sin embargo, estos hechos históricos medievales (el sistema feudal, la creación de ciudades pequeñas y aisladas, y la construcción de las murallas) no son tan importantes a la estructura del argumento de esta novela como en la creación psicológica de los personajes en el ambiente que les rodea. Alfonso Rey explica que la ciudad de Ávila es más bien una prolongación del estado anímico de Pedro. Además, la visión que el narrador nos da de esta ciudad es muy usubjetiva, encaminada sobre todo a reflejar un estado de ánimo" ${ }^{4}$. Edgar Pauk examina el desarrollo de Pedro basándose también en la importancia de Ávila. Según Pauk, Ávila. ciudad famosa por sus místicos, de un clima frío, configura como escenario adecuado para la narracións. La importancia de la ciudad de Ávila es obvia, si el lector se da cuenta de que este personaje comienza su historia en dicha ciudad:

Yo nací en Ávila, la vieja ciudad de las murallas, y creo que el silencio y el recogimiento casi místico de esta ciudad se me metieron en el alma nada más nacer ${ }^{6}$.

\footnotetext{
${ }^{2}$ Mircea Eliade, Images and Symbols: Studies in Religious Symbolism. New York, A Search Book: Sheed and Ward, 1969, pp. 37-39.

"Carlos Blanco Aguinaga, Julio Rodriguez Puértolas, Iris M. Zavala, Historia social de la literatura española. Madrid, Editoriales Castalia, 1979, p. 46.

4 Alfonso Rey, La originalidad novelistica de Delibes. Santiago de Compostela, Universidad de Santiago de Compostela, 1975, p. 26.

s Edgar Pauk, Miguel Delihes: Desarrollo de un escritor (1947-1974). Madrid, Editorial Gredos, 1975, p. 30.

- Miguel Delibes, Obra completa, Tomo I, La sombra del ciprés es alargada. Barcelona, Ediciones Destino, 1964, p. 29. Todas las citas a csta edición van indicadas con el número de la página entre paréntesis.
} 
Aunque pasara muchos años fuera, Pedro escribe el final de la novela también en Ávila: «Me sonreía el contorno de Ávila allá, a lo lejos». (303) Empezando y terminando la novela con referencia a Ávila, ciudad amurallada, el autor crea la ilusión de un marco alrededor de la novela, y así construye con ella una muralla lingüística.

Las murallas de Ávila llegan a ser un punto de partida importante en la vida de Pedro. Lúdico ante la muerte Pedro decide petrificar - eternizarel recuerdo de su amigo, Alfredo, y así llega a ser como la muralla de piedra. La muralla de Pedro es como la de Ávila, la de un mundo donde nada debe cambiar. El error de Pedro radica, claro está, en confundir los limites. Ávila es eterna en tanto que "axis mundi», o sea, templo vivo y fuera de tiempo dentro de su recinto cerrado. Pero el intento de Pedro es errado porque niega la vida y el amor, no por frío, sino porque el dolor lo ciega.

El estado de inmovilidad emocional perdura hasta que Pedro conoce el amor en la ciudad de Providencia:

\footnotetext{
... Se cerraba ahora el parentesis que se abriera la tarde del salvamento del yate, y todo lo que quedaba entre ambos acontecimientos se me hacia tan increible como un sueño o una fuga de la imaginación a los campos absurdos de su influencia. No podía creerlo. Me era imposible aceptar que mi voluntad, tensa y preparada a lo largo de tantos años, hubiese sido doblegada al primer ataque como una frágil caña, por un impetuoso golpe de viento. (204)
}

Con este salvamento, no solamente salva a los habitantes de una nave, sino también se salva a sí mismo. Su antigua manera de ser, su falsa muralla, debería convertirse en una más amplia. Su muralla, a diferencia de la de Ávila, no era para protegerse de poderes mágicos, sino para encerrarle en su propio mundo y dejar que nadie le molestara:

... pero me desarmó la sencilla ingenuidad con que Jane y yo llegamos a compenetrarnos. Jane entró en mí lo mismo que el resplandor de la luna o el lamento del mar, espontáneamente. sin ser buscada. (204)

El lector notará en seguida que Jane no es nombre español, y que tampoco lo traduce Delibes, dándonos a creer que éste quería señalar precisamente la presencia de un elemento extraño. Jane podría haber sido de cualquier ciudad americana. Sin embargo, Delibes la coloca en la ciudad de Providencia. Esto no puede ser por causalidad. La mujer de Providencia llega a penetrar la falsa muralla de Pedro. Si ha de ser aceptada, la vida 
nueva siempre tiene que entrar de una manera suave y sencilla. Jane, como Beatrice, la mujer providencia por excelencia de la Vita Nuova de Dante, es la mujer «providencial» de Pedro. Y para mejor indicar esta relación, Delibes ecoge el nombre de Jane, que podrá ser traducido a italiano a Giovanna. En la Vita Nuova, Dante nos dice que Giovanna es la amiga intima de Beatrice y que ella viene llamada Primavera, porque en un momento determinado, aparece antes de Beatrice:

\footnotetext{
Quella prima è nominata Primavera solo per questa venuta d'oggi; chè io mossi lo imponitore del nome a chiamarla cosi Primavera, cioè prima verrà lo die che Beatrice si mostrerà dopo la imaginazione del suo fedele?
}

Charles Singleton explica que la función de Giovanna es anunciar la llegada de Beatrice, de la misma manera que San Juan Bautista anunció la llegada de Jesucristo ${ }^{8}$. Se basa en los versos de Dante que dicen:

però che lo suo nome Giovanna è da quello Giovanni lo queale precedette la verace luce, dicendo: "Ego vox clamantis indeserto: parate viam Domini»".

Erich Auerbach declara que la interpretación figurativa establece entre dos hechos o personas un vínculo en que uno de éstos no significa solamente a sí mismo, sino también el otro, mientras que el otro comprende el primero $^{10}$. Así que al escoger el nombre de Jane, Delibes también da dos posibilidades coexistentes a esta mujer: la de ser Giovanna (la mujer que anuncia la llegada de algo providencial) y más tarde, la de ser Beatrice (la mujer providencial).

Delibes expone aquí la vinculación de una antigua tradición literaria con esta novela. A través del relato, hay un rasgo evocador que pertenece a la antigua escuela italiana del dolce stil, y sobre todo con la Vita Nuova de Dante. Para poder comprender este hecho, será imprescindible entender lo que es este estilo. El stilnovista alzó el concepto de amor a un nivel elevado. Para este poeta, el amor es un ideal. El sexo, como acto físico, no entraba

\footnotetext{
7 Vita Nuova, Canto XXIV.

${ }^{8}$ Charles S. Singleton, An Essay on the Vita Nuova. Cambridge, Harvard University Press, 1958, p. 22.

- Vita Nuova, Canto XXIV.

10 Erich Auerbach, Studi su Dante. Milano, Feltrinelli Economica, Sp.A., 1977, p. 204.
} 
en este amor. Era un amor puro, en que el intelecto tenía más énfasis que la sensualidad". El amante de la poesía stilnovista está en un mundo en que él no tiene lugar fijo. Se describe a sí mismo como un ser tímido; con una manera humilde y cohibido, puntilloso, cortés, y gentil. La mujer le inspira también con tanto terror que él no la puede mirar, por miedo a que la vista llega a serle fatal, no obstante, éste se fija en ella compulsivamente y vacila constantamente entre la exaltación y la desesperación. Hay también una dulzura que exuda de su poesía, pero tiene el odor de la muerte. Este amante habla mucho de la muerte, y además es una persona introspectiva ${ }^{12}$. El stilnovista plantea la relación de amor verdadero en otra posición. La mujer llega a ser un ideal. Y en cuanto el poeta abstrae de ella su belleza a la forma arquetípica, la mujer como individuo pierde su significado al amante. Entonces, para preservar la individualidad de esta mujer y a la vez, hacer que ella es defensible como objeto de amor racional, es necesario alzarla a un estado de un ser superior: una inteligencia o un ángel ${ }^{13}$. Al convertirla en ángel, el poeta toma el camino más breve del amor para llegar a la caridad. Entonces la idea es que la mujer bella, a quien el poeta dirige su culto, convierte en mensajera de Dios. Sin embargo, el amante de esta mujer angélica es siempre consciente de la dualidad de su natura; el conflicto entre el corazón y la mente es inescapable, y por consiguiente, también la angustia del amante. Característicamente, el amante siempre es pálido y melancólico a causa de esta angustia y típicamente pertenece a media carrera de su vida y amor $^{14}$. El poeta por excelencia de este dolce stil es Dante. Dante dirige su amor puro hacia Beatrice, y aquí la relación entre esta novela de Delibes y la obra de Dante viene a ser más clara. Singleton explica que Beatrice fue la persona que llevó la beatitud del Cielo. Su milagro más importante fue que ella, un ser humano, podía llevar esta beatitud alcanzando los límites de la natura al Cielo porque ella vino del Cielo's.

Miguel Delibes inicia aquí una relación existente entre Jane, la muchacha norteamericana de Providencia, y Beatrice de la Vita Nuova de Dante, con un anillo de matrimonio con la inscripción de Zoroastro: «El matrimonio es un puente que conduce al Cielo». (270). Es la mujer de Providencia quien va a llevar el hombre de Ávila al Cielo. Sin embargo, antes de la aparición de este anillo, la relación Jane/Beatrice, aunque oscurecida, empieza a verter la luz. La primera vez que Pedro y Jane se conocen, es de noche, con la luna llena. La conversación entre los dos era de cosas indiferentes. Sin embargo, durante esta conversación Pedro tiene una sensación inexplicable:

" Maurice Valency, In Praise of Love. New York, Macmillan Company, 1958, p. 206.

12 Ibid., p. 217.

${ }^{13}$ Ibid., p. 227.

14 Ibid., p. 248-252.

is Singleton, p. 6. 
Experimentaba un afán incomprensible de entretener a aquella muchacha para prolongar nuestra innocua conversación hasta el fin del tiempo, hasta el limite de la resistencia humana. (192)

Pedro, sin darse cuenta, empieza a idolatrar a esta mujer norteamericana. No entiende la razón por la cual quiere pasar el tiempo con ella. Sin embargo, ya comienza a ver que la vida humana no tiene límites, y, que hay cosas que vienen del otro mundo; en este caso la providencia y la beatitud de Pedro vienen de la ciudad de Providencia, en la figura de Jane. Tal como los stilnovisti, Miguel Delibes comienza a caracterizar a esta mujer con cualidades angélicas.

Para el poeta stilnovista, los ojos de la mujer amada tienen una importancia enorme. Los ojos son el mecanismo del enamoramiento. Este mecanismo llega a ser explicable en términos del movimiento de los espíritus del alma de una persona a la de otra persona. La luz es el intermedio, y la brillante mirada viene de los ojos de la mujer y penetra el ojo del hombre y finalmente plantea en el corazón de éste ${ }^{16}$. Delibes también usa este concepto en cuanto describe el efecto que los ojos de Jane tiene durante la iniciativa de la relación:

...La miré a los ojos inquiriendo de ella qué había observado en mi ... Ella comprendió la intención de mi mirada. (194)

...Volvió rápidamente a mí sus ojos intensamente claros ... su intensa mirada al tiempo... (196)

...Luego cerré los ojos temiendo que mi excitación se transparentase en ellos, ... (196)

... de que veía mi cerebro a través de mis ojos con una nitidez diäfana. (201)

...La mirada clara de sus ojos clavados en los míos ... en mi retina. (209)

...Se me veía por dentro ... (211)

Pedro se entera de que a través de los ojos, no solamente los de Jane, sino también los suyos, Jane ha podido penetrar su ser, su falsa muralla, su mundo sacro. La referencia aquí tiene que ver con el poder místico que Pedro atribuye a los ojos. A un nivel más amplio, es este poder mágico que penetra la muralla de Pedro y esta muralla, la ha construido precisamente para no dejar penetrar las cosas mágicas ni místicas. Sin embargo, no solamente la mirada de Jane penetra el alma, o en este caso, la falsa muralla

16 Valency, p. 221. 
de Pedro, sino que los suyos también horadan la oscuridad. En la Vita Nuova, Dante afirma que también sus ojos penetran la sombra con visiones en las que ve la muerte de Beatrice. Nótese que cuando tiene estas visiones, y son tres, no se da cuenta del significado. Aun pide el significado de su primera visión a varias personas y una (Guido Cavalcanti) explica que esta visión muestra que Dante había visto la virtud. No obstante, en aquel entonces, nadie podía interpretar bien esta visión ${ }^{17}$. Después de la muerte de Beatrice, ve claramente lo que querían decir: «La verace giudicio del detto sogno non fue veduto allora per alcuno, ma ora è manifestissimo a li più semplice" ${ }^{18}$.

En esta novela de Miguel Delibes, Pedro coincide con Dante en que él también tiene tres visiones que anuncian de antemano la muerte de Jane, su mujer providencial, y tanto como Dante, las interpreta equivocadamente. Dante tiene dos visiones mientras dormía y la última en un delirio. Nuestro protagonista las experimenta, una vez en un estado hipnotizado, las otras dos en un sueño, incluso en éstas, una visión en un delirio. (206; 241-242; 292) En ambos casos, poco después de la última visión, muere la mujer angélica. Simbólicamente, esta última visión de Pedro hace que la relación entre Jane y Beatrice sea más estrecha. Esta última visión se le ocurre a Pedro al volver de España en una nave, minutos antes de llegar a la costa de Providencia. Pedro mismo afirma que su visión no le asustaba en sí: "Entonces advertí que durante mi sueño no había existido el menor asomo de violencia». (293) Aquí el simbolo de la nave, la salvación, queda muy claro; está a la frontera, a los límites de la Providencia, tierra no sólo natal de Jane, tierra prometida de ella. Pero, para reforzar esta imagen, Pedro nos dice que para tranquilizarse de esta visión, mira un retrato de su mujer, firmado "With everlasting love..." (293) Era la palabra "everlasting» que daba fastidio a Pedro, no la visión, porque siempre asociaba esta palabra con la muerte.

Dante no quiere hablar de la muerte de su amada: «...non è lo mio intendimiento di trattarne qui .... ${ }^{19}$ Tampoco Pedro quiere elaborar de la muerte de Jane, sólo nos dice: «Cuando extrajeron su cadáver una hora más tarde estaba nevando". (294) Pedro, como Dante, quiere abandonar la oscuridad. Y para mejor indicar la manera de escapar de este mundo salvaje y oscuro (un mundo equivocado, un mundo de error, como la falsa muralla que se edificó Pedro tras la muerte del amigo) para entrar en el Paraíso, Delibes utiliza la inscripción de Zoroastro: «El matrimonio es un puente que conduce al Cielo». (270) Y como este puente une a Pedro y Jane, también indica la relación posible entre Delibes y Dante. El hombre ya va a

\footnotetext{
17 Singleton, p. 14.

18 Dante Alighieri, Vita Nuova. Milano, Rizzoli Editore, 1952, Canto III, p. 13.

'9 Dante, Canto XXVIII.
} 
huir de su tumba y seguir la vía de la felicidad. La ironía aquí es que Pedro viene a conocer a Jane salvándole la vida en un incidente marinero, pero es Jane quien al fin y al cabo, llega a salvar la vida de Pedro, dándole la oportunidad de escapar de su selva oscura.

Entonces, los indicios de una relación entre esta novela y los stilnovisti parecen ser evidentes ya que vemos a Pedro, a media carrera (de no solamente su vida profesional sino también su vida misma), con una introspección tremenda, encuentran a su mujer angélica para llevarle al camino hacia el Paraíso. La referencia a la Vita Nuova de Dante viene, a pesar del hecho de que es el stilnovista por excelencia, a causa de las repetidas veces en que Pedro alude a su nueva vida encontrada con Jane (pp. 204-205; 264). 